\title{
La hora del cuento en la biblioteca pública. Un análisis de las prácticas de lectura
}

\section{Story Time in the public library. An analysis of reading practices}

YolAndA GONZÁLEZ DE LA TORRE*

El objetivo de este trabajo fue identificar y analizar algunas prácticas de lectura visibles en una biblioteca pública de Guadalajara, México. Desde una perspectiva sociocultural que considera la lectura como una práctica, se reconocen las condiciones y demandas que enfrenta el lector en un determinado espacio y lo llevan a desarrollar la actividad lectora de cierta manera. Se eligió como espacio de indagación "La hora del cuento", actividad dirigida a un grupo infantil de visitantes asiduos de esa biblioteca. Los instrumentos para la recolección de datos fueron la observación, que permitió registrar las acciones de quienes intervinieron en las actividades de lectura, y la entrevista a las bibliotecarias y participantes de la actividad, que dio cuenta de algunas de sus percepciones sobre el fomento de la lectura y la formación de lectores. Los resultados indican que las prácticas en ese lugar se centran en la difusión del acervo, así como en acentuar rasgos del lector valorados en la cultura escolar, como la fluidez lectora, a través de ejercicios como la lectura en voz alta.

This work analyzes visible reading practices, which were identified in a public library in Guadalajara, Mexico. Based on a sociocultural perspective of reading as social practice, we focused on the particular conditions and demands that the reader faces in a given space and leads him to develop reading activity in some specific way. The activity named "Story Time", carried out in the library addressed to the children's who are regular visitors, was chosen to develop our inquiry. Two methods of qualitative social research were used: Observation and interviews with the librarians in order to identify reading practices as well as their perceptions of the promotion of reading and readers' training. Concluding remarks show that the emphasis of this activity was placed on the dissemination of the library collection, along with promoting the reader's abilities the most appreciated in the school culture, such as reading fluency, through exercises such as reading aloud.

\section{Palabras clave:}

prácticas de lectura, biblioteca, fomento de la lectura, formación de lectores

Keywords: reading practices, library, reading promotion, reading education

Recibido: 29 de junio de 2020 | Aceptado para su publicación: 12 de octubre de 2020 |

Publicado: 11 de enero de 2021

Recuperado de: https://sinectica.iteso.mx/index.php/SINECTICA/article/view/1173 doi: 10.31391/S2007-7033(2021)0056-002

\footnotetext{
* Doctora en Educación por la Universidad de Guadalajara. Profesora-investigadora en el Departamento de Estudios en Educación de la Universidad de Guadalajara. Líneas de investigación: procesos de lectura y escritura, cognición y aprendizaje. Correo electrónico: ygtorre@hotmail.com/ https://orcid.org/0000-0003-0110-0030
} 


\section{INTRODUCCIÓN}

T a lectura es un instrumento esencial para obtener información y construir conocimiento. En la actualidad, se reconoce la importancia de que las personas

cuenten con prácticas lectoras adecuadas que les permitan resolver una tarea no solo escolar, sino de la vida diaria, como hacer un pago, tramitar un permiso, comprar un boleto para viajar, entre otras. De esta manera, profesores e instituciones se preocupan por que las personas reconozcan en la lectura una actividad que les facilite un desarrollo a lo largo de la vida. Asimismo, cuando se piensa en los lugares en los cuales se aprende a leer, predomina la escuela, porque a ella se le ha otorgado socialmente esa responsabilidad (Rockwell, 2001).

Otras posiciones sostienen que la formación lectora no solo corresponde a la escuela, sino que existen otros espacios donde se llevan a cabo actividades con la intención de propiciarla, como las iglesias, los hogares y las bibliotecas públicas. En estos espacios, el lector encuentra formas de acercarse y usar los textos (Bolaños, 2015). Por otra parte, los proyectos y programas tendentes a fomentar, fortalecer o remediar el desarrollo de la lectura se implementan, en la mayoría de los casos, también para incidir en el interés por la lectura (Duarte, 2005; Yépez, Ceretta y Díez, 2013).

Hasta hace unas décadas, las bibliotecas representaban espacios privilegiados para leer, incrementar el acervo de conocimientos y ejercitar el gusto personal por la lectura. Esta idea era consolidada por organismos diversos. La Federación Internacional de Asociaciones de Bibliotecarios y Bibliotecas (IFLA, por sus siglas en inglés), durante la década de los noventa (Niegaard, 1994), sostenía a la biblioteca pública en particular como un centro que permitía a los usuarios variedad de conocimiento e información. Se le concebía como un espacio importante en la educación y la cultura, por lo que se consideraba primordial que toda persona tuviera acceso a ella. Durante los años siguientes, se le atribuyó a la biblioteca el papel de un sitio destinado al fomento de la lectura (IFLA/Unesco, 1994, 1999, 2010), y se le encomendaron otros objetivos:

- Crear y consolidar hábitos de lectura en los niños y las niñas desde los primeros años.

-Estimular la imaginación y creatividad de niños y jóvenes.

-Prestar apoyo y participar en programas y actividades de alfabetización para todos los grupos de edad y, de ser necesario, iniciarlos.

En el caso de México, la evolución de la biblioteca pública ha atravesado por una serie de planes y programas para impulsar en la población el gusto por la lectura. Como ejemplos se implementaron los programas La hora del cuento a partir de 1996, dirigido a niños y niñas de primaria y, en 1997, el Círculo de lectura para jóvenes, a través de la Dirección General de Bibliotecas Públicas, adscrita al Consejo Nacional para la Cultura y las Artes (DGB/Conaculta, 2003, 2013), además de otras actividades complementarias, como la exposición bibliográfica; estos programas están aún vigentes en las bibliotecas. Reconocer estos esfuerzos implica también hacer una distinción: el fomento de la lectura es parte de la formación de lectores, pero no la abarca en su totalidad. Esta última encierra, hasta cierto punto, acciones para la mejora de las habilidades y competencias de lectura de las personas. 
Con relación a lo anterior, el desempeño lector de jóvenes mexicanos en pruebas realizadas por la Organización para la Cooperación y el Desarrollo Económicos (OCDE), a través del Programa Internacional para la Evaluación de los Estudiantes (Informe PISA, por sus siglas en inglés), siempre ha estado debajo del promedio de los países integrantes de esta organización, muy alejados de aquellos de los países con mayores resultados, como Finlandia, Corea, China y Singapur (PISA/OCDE, 2000, 2003, 2006, 2009, 2012 y 2015). Pretender con ello decir que los estudiantes mexicanos son menos competentes para leer sería una afirmación aventurada si no se consideran factores en torno a su práctica no solo al interior de las escuelas.

En nuestro país, los esfuerzos para la promoción de la lectura tienen entre sus principales antecedentes la Red Nacional de Bibliotecas Públicas (RNBP), creada en 1983 con el propósito de impulsar el desarrollo cuantitativo y cualitativo de los servicios bibliotecarios en todo el territorio nacional. Ese mismo año, en cada una de las entidades federativas se formó una red estatal y, en 1986, los municipios con más de treinta mil habitantes contaban con una biblioteca municipal, de acuerdo con datos de la DGB del Conaculta (2013). Esa misma dependencia define como biblioteca pública todo establecimiento que contenga un acervo de carácter general superior a quinientos títulos catalogados y clasificados, con la capacidad para proporcionar gratuitamente diversos servicios y recursos de acceso a la lectura a todos los habitantes de una comunidad.

Los servicios básicos que toda biblioteca ofrece según la RNBP son: préstamo interno con estantería abierta, préstamo a domicilio, servicios de consulta, orientación a usuarios, fomento de la lectura, módulo de servicios digitales con acceso a internet, colección Braille, videoteca, hemeroteca, ludoteca, sala de usos múltiples, sala juvenil y sala multimedia; todo ello, de acuerdo con sus dimensiones, recursos y nivel de desarrollo.

Las acciones que se desprenden de esta variedad de servicios, aun cuando existe una reglamentación para su implementación en los manuales proporcionados por la DGB/Conaculta a cada biblioteca, varían dependiendo del espacio físico disponible, del flujo de usuarios y del personal con que se cuente para el desarrollo de las actividades, lo que da lugar a opciones como La hora del cuento, Círculo de lectura, Exposición bibliográfica, Tertulias y Videoanálisis, entre otras.

Los anteriores programas coinciden en la manera de promover la lectura en la población mediante acciones que permiten acercar el acervo bibliográfico y otros materiales a los usuarios, así como impulsar la consulta de los textos, en concordancia con la función que corresponde a la biblioteca. Sin embargo, la formación de lectores implica diferencias conceptuales respecto al fomento de la lectura. Cuando se habla de formación se hace referencia a dar forma a las disposiciones de una persona y poner en juego las capacidades para una actividad particular (Larrosa, 2003; Moreno, 2005). En el caso de la lectura, estas capacidades estarían dirigidas en principio a construir significado de lo que se lee (Almada, Duarte, Etchemaite y Seppia, 2001; Duarte, 2005), aunque parte de la formación de lectores supone la definición del tipo de lector que se quiere formar y de lo que se considera un buen lector (Bermúdez, 2012).

En este sentido, a pesar de la existencia de muchas iniciativas de fomento de la lectura como las encabezadas por la RNBP, hay posturas críticas sobre las campañas lectoras.

González. La hora del cuento en la biblioteca pública. Un análisis de las prácticas de lectura Sinéctica 56 www.sinectica.iteso.mx 
Argüelles (2002), por ejemplo, afirma que en algunas de ellas se promueve la lectura con razones equivocadas, como cuando se afirma que la lectura hace "importantes" a las personas; este resulta, por lo demás, un argumento falso, porque en el mundo abundan las personas "importantes" que no solo no leen libros, sino que, por si fuera poco, se muestran orgullosos de no haberlos necesitado para hacerse "importantes"

Con base en lo anterior, existen diferentes escenarios donde la lectura tiene lugar y la biblioteca pública, además de la escuela, pareciera el espacio ideal para su desarrollo. El estudio que aquí reportamos explora cuáles son las condiciones o las demandas lectoras a las que se enfrenta un lector al participar en una actividad de fomento a la lectura, como La hora del cuento. Elegimos esta última porque, de todas las actividades de fomento a la lectura que se promocionan en la biblioteca, es la única a la que asisten participantes de manera regular; lo anterior lo corroboramos en visitas anteriores al inicio del estudio.

\section{LA LECTURA Y SU FOMENTO COMO PRÁCTICAS DE ORDEN SOCIOCULTURAL}

La perspectiva desde la cual concebimos en este trabajo la lectura y las acciones destinadas a su fomento y a la formación de lectores en la biblioteca pública sostiene que estas se desarrollan dentro de una interacción en la cual actores de un grupo o institución participan en la construcción de prácticas específicas (Barton \& Hamilton, 1998, 2000; Carlino, 2005; Martos y Guerrero 2011). La lectura adquiere un carácter de práctica social útil para la obtención de información y la adquisición de saberes, y también como un medio para interactuar con personas y resolver tareas de la vida cotidiana, por ejemplo, al efectuar trámites económicos (solicitar un crédito, pagar un servicio), participar en actividades sociales (asistir a un acto, preparar un curso), comunicarse con otros (enviar y recibir mensajes de texto, desenvolverse en redes sociales), entre otras.

Esta perspectiva apunta cómo determinados espacios institucionales constituyen entornos donde se usa y valora la lectura, los cuales imprimen ciertas peculiaridades a la práctica lectora. En tales entornos se distinguen dimensiones como el ambiente de interacción o situación en que se desarrolla la lectura, los participantes, el texto, las actividades que se realizan, y las normas usuales que regulan la comunicación (Kalman, 2002, Zavala, 2011; Martos y Guerrero, 2011). En suma, desde esta visión se define la práctica lectora como la actuación del lector en un medio cultural donde enfrenta distintas demandas y condiciones (González, 2013).

Fundamentalmente, la perspectiva teórica con la que se abordó la investigación analiza la lectura en su carácter de actividad sociocultural, por lo cual destacamos las interacciones de las personas que intervienen en el espacio estudiado. Desde esta visión, la lectura es una actividad cognitiva, pero también implica intereses, demandas del contexto en que se realiza y materiales determinados que, en su conjunto, pueden provocar en los sujetos la aparición de acciones constituidas como estrategias no tanto para fines como entender, sino para cumplir con lo que en un entorno se exige.

En cuanto a la formación de lectores que se da en los contextos, Álvarez y Naranjo (2003) señalan que la biblioteca pública debe ser considerada una zona de práctica donde se afiance una representación social del lector, es decir, que los bibliotecarios comprendan que el lector que acude a la biblioteca tiene una serie de ideas acerca 
de la lectura, concretamente sobre qué y cómo debe leer. Así, una de las tareas centrales de las personas encargadas de una biblioteca es formar usuarios para que puedan aprovechar los recursos y servicios que se ofrecen (García-Gómez y DíazGrau, 2007); de esto se desprenden formas peculiares con las que se intenta favorecer el fomento de la lectura y la formación de lectores.

Con relación a la primera de esas finalidades, a partir de lo establecido por la IFLA, diferentes organismos internacionales han emprendido una serie de programas para fortalecer y ampliar el impacto de la biblioteca pública y, con ello, la incorporación de actividades destinadas a favorecer la actividad lectora en la comunidad. Uno de ellos fue el Proyecto Pulman: Public Libraries Mobilising Advanced Networks (Movilización de las bibliotecas públicas en redes avanzadas). Compuesto por 40 países, ante todo europeos, este proyecto estableció pautas para el desarrollo $\mathrm{y}$ fomento de la lectura en diferentes dispositivos, y para personas en diversas circunstancias (incluye a débiles visuales y a las que tienen problemas de lectura, como la dislexia, por ejemplo). Lo que pretendía este programa era acercar los libros a los usuarios aprovechando las tecnologías de la información para explotar al máximo sus posibilidades y, así, generar mayor inclusión social (Pautas Pulman, 2002).

Otras iniciativas son el Plan Iberoamericano de Lectura, a cargo del Centro Regional para el Fomento del Libro en América Latina y el Caribe (CERLALC, 2004), el Proyecto ILIMITA (CERLALC, 2007) e Iberbibliotecas (CERLALC, 2012). En ellos se introduce la noción de formación de lectores y escritores, así como el acceso al libro a toda la población a través de las bibliotecas escolares y públicas.

Investigaciones en el contexto latinoamericano revelan intereses similares en lo referente a acercar los lectores a los textos de las bibliotecas públicas, aunque con mayores precisiones en términos de los actores que intervienen en las iniciativas de fomento de la lectura. En México, Ortega (2006), en un estudio etnográfico en una biblioteca pública, encontró que quienes promueven la asistencia a la biblioteca son, principalmente, las profesoras de las escuelas primarias, mientras que los niños asisten para resolver tareas escolares y las bibliotecarias aprovechan su estancia para incorporarlos a los talleres y actividades de fomento de la lectura; de ese modo, se convierten en participantes cautivos, en gran medida porque en la biblioteca pública, según confirman los sujetos de ese estudio, "pueden elegir lo que quieren leer". En este sentido, Sevilla (2007) destaca la prioridad de discutir si quien asiste a la biblioteca se le considera como usuario, cliente o público en general, pues de la definición construida se desprenden actividades específicas.

Por su parte, Álvarez, Giraldo, Rodríguez y Gómez (2008) exploraron bibliotecas públicas de Colombia y encontraron que la promoción de la lectura se realiza de manera aislada y se dirige solo a población infantil y juvenil, y deja de lado a los adultos, aun cuando la lectura se ha publicitado como uno de los factores que permite vincular a la institución con la sociedad. Además, observaron que las actividades de lectura están ligadas a otras adicionales con la intención de que resulte atractiva, como las manualidades o el montaje de obras de teatro. Estos autores, asimismo, distinguen un cambio de paradigma en el que, a partir de la incorporación de lo digital, "ya no se ve a la biblioteca pública como el centro de información y conocimiento". Para otros (Hernández, 2001; Labra, 2005; Margaix-Arnal, 2008; Pérez y Gómez, 2010), la llegada de las tecnologías digitales no desplaza, más bien complementa las 
funciones de las bibliotecas públicas, al contribuir a diversificar las fuentes de información e interactuar con otros lectores para recomendar y valorar distintos textos.

En otros estudios, como el de Caro (2013), se asevera que la biblioteca pública es un espacio institucional de formación de lectores y ciudadanos capaces de desenvolverse en una cultura letrada. Esta investigación se desarrolló desde una perspectiva etnográfica; se registraron y caracterizaron las actividades de fomento de la lectura que se llevan a cabo en la biblioteca pública en Bogotá, Colombia. Los resultados reportados señalan que existe una serie de actividades (talleres, tertulias, club de lectura, entre otros) que dan lugar a lo que el autor denomina "el acto lector", constituido por la lectura en voz alta y socialización de lo leído con otros participantes o el bibliotecario. Estas prácticas de lectura conforman "circuitos lectores" cuyos elementos fundamentales son el acceso y la disposición de materiales de lectura.

El club de lectura también ha sido estudiado en la biblioteca pública; sin embargo, a diferencia de La hora del cuento, aquel está dirigido a lectores adultos. Consiste en que los participantes realizan la lectura previamente en casa y asisten a discutir o comentar el contenido de lo leído. En este tema, Agustín y Morera (2016) y Álvarez (2016) identificaron el perfil de quienes participan en esta actividad y observaron que asisten más las mujeres; los materiales de lectura que más se utilizan corresponden a textos literarios y, en ocasiones, se llevan a cabo actividades asociadas, como presentación de libros, obras de teatro o conferencias de autores. El segundo de estos trabajos citados profundiza su análisis por medio de entrevistas y señala que los participantes son lectores asiduos y, aunque ya cuentan con trayectorias lectoras, reportan mejoras en su habilidad lectora y una revaloración de la lectura, la cual se evidencia en altos niveles de motivación hacia la práctica de esta actividad.

Considerar la biblioteca pública una institución que participa a través de sus servicios y programas en el fomento de la lectura hace visible la pertinencia de indagar más acerca de las formas en que se llevan a cabo las actividades de fomento de la lectura y de cómo se genera la participación lectora de los usuarios y qué materiales se ponen a su disposición. Estas inquietudes en su conjunto desembocan en la pregunta que orientó este trabajo: ¿qué tipo de prácticas de lectura se promueven en la biblioteca pública?

\section{Metodología}

Este trabajo comprende una aproximación cualitativa a la actividad lectora desarrollada por usuarios de una biblioteca pública en relación con las orientaciones de los bibliotecarios. Se trata de un estudio de caso, por lo cual no se pretende hacer una generalización de los hallazgos, sino caracterizar cómo se da un fenómeno en un contexto de interés particular (Yin, 1984; Arnal, Del Rincón y Latorre, 1992; Stake, 1978, 2000). Buscamos dar cuenta del modo en que se moldean prácticas de lectura en medio de las actividades promovidas en ese sitio. La población en estudio estuvo representada por lectores y personal bibliotecario durante la actividad denominada La hora del cuento. La DGB (Conaculta, 2002) establece que esta es una actividad de fomento a la lectura dirigida al público infantil, para la cual el bibliotecario debe elegir un cuento del acervo de la biblioteca; leerlo detenidamente y en voz alta; ambientar el espacio en donde se llevará a cabo la actividad; y elaborar carteles para difundir al interior y exterior de la biblioteca. 
El lugar donde efectuamos el estudio es una biblioteca pública municipal, ubicada en una colonia del área metropolitana de Guadalajara, con una población de clase media baja de acuerdo con la clasificación que hace el Consejo Nacional de Población (Conapo) de México (Conapo, 2012). La biblioteca se sitúa dentro de una unidad administrativa municipal y comparte espacio con un centro cultural en el que se imparten cursos de corte y confección, danza, superación personal y educación continua. En los alrededores de la biblioteca se ubican seis centros preescolares, nueve escuelas primarias, cuatro secundarias y una preparatoria de una universidad pública. Colinda con la unidad administrativa un jardín de niños y un templo católico.

La biblioteca se compone de un espacio de recepción con muebles cómodos para lectura y una exposición bibliográfica de las novedades que llegan ya sea por donaciones o por asignación de la DGB, instancia oficial a cargo de estos sitios. Tiene cuatro áreas respectivamente asignadas como sala infantil, sala general, sala de consulta y una cuarta para exposiciones de pintura, escultura, grabados y otras manifestaciones de arte. Cuenta con un acervo de 18,000 volúmenes y tres equipos de cómputo, los cuales estaban descompuestos al momento de las observaciones. El personal se compone de tres bibliotecarios generales y una directora. Dos de ellos van por la mañana y los otros dos, por la tarde (entre ellas la directora).

Para comprender y representar la visión particular de cada uno de los actores implicados en la interacción producto de las actividades en esta biblioteca, consideramos instrumentos pertinentes como la observación y la entrevista. La decisión de emplear el primero también se basa en la revisión de estudios previos, como los de Agustín y Morera (2016) y Álvarez (2016), que sugieren que observar a los usuarios de las bibliotecas públicas permite distinguir sus necesidades, los recursos ofrecidos y, en algunos casos, acciones estratégicas para gestionar información.

Para dirigir la observación en la biblioteca, definimos dos unidades guía: escenarios y materiales de práctica lectora, y usos de la lectura en las actividades de La hora del cuento. La primera de estas unidades integra el registro de características del lugar donde se desarrolla la actividad, como su ambientación, equipamiento y condiciones materiales en general. La segunda comprende acciones particulares que se lograron identificar, como la lectura en voz alta, la lectura en silencio, la "actuación de la lectura" y la elaboración de escritos o dibujos, entre los más importantes.

Otros de los aspectos que consideramos durante la observación fueron las interacciones generadas entre los participantes de la actividad a partir de los textos y la función que cada uno de ellos realizaba con ellos desde el rol que desempeñaban en la biblioteca. Llevamos a cabo seis sesiones de observación, cada una considerando los elementos incluidos en el formato del siguiente registro:

\begin{tabular}{|c|c|c|}
\hline $\begin{array}{l}\text { Fecha } \\
\text { Número } \\
\text { Sitio }\end{array}$ & observación & \\
\hline $\begin{array}{l}\text { Hora de } \\
\text { registro }\end{array}$ & Descripción de actividad & Notas \\
\hline & & \\
\hline
\end{tabular}


En este caso el grupo observado estuvo formado solo por cinco niñas que asistían a La hora del cuento, de entre nueve y once años de edad, todas ellas alumnas de primaria. El segundo instrumento, la entrevista semiestructurada, tuvo como cuestiones clave de indagación:

-El rol en las actividades como bibliotecario.

-Los conceptos de lectura, lector, buen lector, fomento de lectura.

- La percepción de ambos actores sobre el desarrollo de las actividades relacionadas con la lectura, en términos de fines, materiales y otros aspectos cualitativos.

-El ejercicio y las capacidades de los bibliotecarios.

-Las estrategias de lectura de los usuarios.

- Las reglas establecidas por la institución para llevar a cabo las actividades.

Hicimos dos entrevistas a bibliotecarias a cargo de La hora del cuento y dos más a dos usuarios participantes en ella. Las entrevistas se audiograbaron y transcribieron para su posterior análisis. El procedimiento para el análisis de los datos consistió en un proceso continuo de revisión y comparación de la información recabada; nos basamos en las categorías teóricas para obtener rutinas y patrones que nos ayudaron a comprender y explicar las prácticas lectoras en este contexto.

\section{RESULTADOS}

Los resultados que exponemos en seguida están organizados, para fines de explicación, en dos apartados acordes con las categorías principales que conforman la práctica lectora. Cabe señalar que, dada la complejidad del fenómeno lector, resulta difícil presentar de manera aislada cada una de ellas, puesto que tanto los participantes, fines u objetivos y textos de lectura se encuentran entrelazados en el contexto donde se da la lectura como una actividad social.

\section{El contexto lector y sus participantes. Ideas acerca de leer}

Cuando hablamos de contextos lectores, no solo consideramos las condiciones materiales y físicas de un lugar donde se lleva a cabo la lectura; también comprende las interacciones de las personas que en él participan y los intercambios que se generan a partir del uso de los textos.

Una primera cuestión que podemos señalar respecto a la lectura en la biblioteca es que la distribución de los espacios y los materiales de lectura dispuestos en cada una de ellos delimitan las actividades de lectura que ahí se efectúan y de quienes participan. La biblioteca está organizada por salas y en cada uno de ellas se ubican ciertos textos o materiales de lectura y, de igual forma, en cada uno de estos lugares se llevan a cabo determinadas actividades (cuando hay asistentes); por ejemplo, en la sala de consulta, que es un espacio aledaño a la recepción de la biblioteca, se exponen los textos que han llegado de manera reciente para formar parte del acervo; los libros son ubicados en mesas para que puedan ser tomados y revisados. 
Otro de los espacios es la sala general, en la cual tiene lugar el Círculo de lectura, que fomenta la lectura dirigida a usuarios adultos; sin embargo, en el tiempo en que se realizó este estudio en ninguna ocasión esta se ofreció por falta de participantes. En la sala infantil se encuentra la colección de libros infantiles y en ella se desarrolla una vez a la semana La hora del cuento, que se brinda a los niños.

En el caso de los participantes en este contexto, encontramos a los bibliotecarios, cuya función es establecer acciones que favorezcan el funcionamiento de la biblioteca; entre sus responsabilidades (de acuerdo con los manuales de la DGB), destaca el dar mantenimiento a los libros, cuidar su uso, así como organizar y promocionar las actividades de fomento a la lectura. Desde el punto de vista de las bibliotecarias entrevistadas, la tarea principal es atender a los usuarios (cuando decimos usuarios, nos referimos a usuarios de la biblioteca en general, y cuando decimos usuario-lector, indicamos a los participantes en La hora del cuento) y promover los libros:

La función principal es atender a los usuarios, es la principal; la otra es dar a conocer los libros que hay y que llegan, por ejemplo, en ocasiones cuando haces alguna actividad con los niños los finales del cuento lo dejas sin terminar o se las dejo, así como que al final medio les cuento el final para que ellos vengan, y luego me preguntan ¿tiene el libro en la biblioteca?, ¿sí lo presta? Y le contestamos: "Sí, ve y haz tu trámite de la credencial, te lo prestamos por ocho días y te lo llevas a tu casa..." (entrevista bibliotecaria 1).

Pues [...] yo creo que lo importante es que la gente venga y lea o se lleve los libros a su casa, que se usen los libros pues (entrevista bibliotecaria 2).

Como se registró en los comentarios anteriores, las bibliotecarias entrevistadas resaltan la promoción de los libros sobre el fomento de la lectura. De igual forma, las bibliotecarias se encargan del acceso a los libros; ellas deciden qué deben o pueden leer los asistentes a la biblioteca, ya sea para una tarea escolar o para participar en las actividades de lectura. Esto es importante porque la biblioteca pública es de estantería abierta, es decir, el acceso a los libros y materiales es libre; no obstante, el cuento que se lee es elegido por el bibliotecario y no se ofrece la posibilidad de seleccionar o proponer algún otro. Cuando los niños piden leer otro texto, las bibliotecarias no aceptan, pero les dicen que el cuento que desean leer lo pueden pedir prestado y llevarlo a casa. Eso contrasta con lo encontrado en trabajos como el de Ortega (2006) sobre la posibilidad de los niños de elegir lo que quieran leer, aunque puede estar motivado por el hecho de que las bibliotecarias tenían preparado cierto guion de trabajo para determinado relato.

De manera excepcional, uno de los días observamos una visita guiada, en la que un grupo de 33 niños y niñas de cuarto de primaria fueron llevados por sus profesores a visitar la biblioteca; los bibliotecarios los orientaron sobre el acervo disponible, además de las actividades y servicios que ofrecen. Luego, se les leyó un cuento; después pasaron a los estantes de los libros y les indicaron que tomaran el libro que más les gustara y se sentaran a leerlo de manera individual, aunque, como advertimos en el siguiente fragmento, esa elección está sujeta a reglas de operación de la biblioteca:

Algunos de los niños se acercan a la exposición bibliográfica, toman los libros que la conforman, los hojean, otros niños toman libros de diferentes estantes y eligen; seis de los niños van a la estantería en la que se encuentran libros del área 500 de acuerdo con el sistema Dewey, la cual incluye a las ciencias naturales y matemáticas. Eligen algunos

González. La hora del cuento en la biblioteca pública. Un análisis de las prácticas de lectura Sinéctica 56 www.sinectica.iteso.mx 
textos y se sientan en el área; en seguida, llega una de las bibliotecarias y les dice que se retiren de esa área y les menciona que esos libros no se toman y que los dejen, ante esto uno de los niños le dice que el otro bibliotecario les dijo que tomaran el libro que quisieran y a ellos esos les habían llamado la atención. Ante ese reclamo, la bibliotecaria contestó que estos libros no, solo aquellos y señaló hacia otros estantes de la biblioteca; los niños se retiraron de ese espacio y se acercaron con sus compañeros que ya se encontraban leyendo en silencio o en voz alta a comentar u hojear un libro con ellos (observación 4 en la biblioteca).

Cabe señalar que los libros que son parte de la clasificación 500, al igual que el resto de las colecciones, son de estantería abierta y pueden ser tomados por cualquier usuario; además, tampoco estaban en reparación o con algún aviso de no tomarlos. Lo recuperado en el fragmento anterior da cuenta de que algunos bibliotecarios guardan disposiciones diversas al atender población infantil, en ese caso. Parte de ello se explica por la propia organización que existe entre ellos, como se refleja en el siguiente fragmento de entrevista (las letras B, UL y E, que aparecen en el registro de las entrevistas, se refieren a la identificación de quienes participaron en ellas: B para bibliotecario/a, UL para participante en la hora del cuento y E para la entrevistadora):

B. En ocasiones a algunos de mis compañeros no les agrada mucho trabajar con los niños en actividades así (La hora del cuento), prefieren la atención de usuarios.

E. ¿Entonces no todo el personal bibliotecario imparte La hora del cuento?

B. Bueno, es que nos repartimos todas las tareas de la biblioteca, que la reparación de libros, que el préstamo a domicilio, que las visitas guiadas y por lo general entre dos o tres de los compañeros nos encargamos de La hora del cuento. Todos tenemos la capacitación de todos los talleres para trabajar en la biblioteca, pero la directora nos da la posibilidad de elegir la actividad que más nos guste, aunque sí nos ha tocado a todos desarrollar alguna actividad de fomento de la lectura (entrevista bibliotecaria 1).

En este sentido, la actuación de los bibliotecarios es más la de apoyo técnico a los usuarios, pues la pretensión de cumplir como mediadores que amplían y robustecen las experiencias de lectura de los usuarios (Duarte, 2005) no parece alcanzarse en este caso.

Otro de los participantes que convergen en el espacio bibliotecario son los usuarios. Según los registros obtenidos, quienes asisten a la biblioteca por lo general son menores, estudiantes de primaria y secundaria. En ocasiones, concurren adultos a consultar publicaciones periódicas, como los diarios y algunas revistas. Los bibliotecarios señalan que la población adulta va de manera esporádica y durante breves lapsos, y aunque se les invita a las actividades de fomento de la lectura no aceptan participar; la mayoría de las veces argumentan que no tienen tiempo. Otras veces acuden adultos solo como acompañantes de los niños y jóvenes.

Por lo regular, en los usuarios que visitan la biblioteca predomina la necesidad de realizar tareas escolares; buscan información sobre cuestiones como la biografía de algún personaje o las efemérides del mes, las cuales recuperan mediante una fotocopia o con apuntes en el cuaderno. Observamos que ante la demanda de los usuarios de resolver tareas escolares, en ocasiones, los bibliotecarios ya tienen lista esta información; entregan material fotocopiado en vez de conducir al usuario a los libros o proporcionarles un libro. Esto origina que quienes visitan la biblioteca no permanezcan en ella más de cinco minutos. 
Como apreciamos en lo expuesto, las funciones de los bibliotecarios y la manera que las realizan conforman patrones de actuación centrada en el uso de los textos y delinean la forma de participación e interacción de los usuarios y de los usuarioslectores. Ahora bien, hemos revisado cómo los usuarios ajustan su necesidad de información y lo que leen a lo que se ofrece por parte de los bibliotecarios; en este punto, cabe preguntarnos respecto de las ideas de bibliotecarios y usuarios acerca de lo que es la lectura y qué es ser buen lector.

En el caso de los bibliotecarios responsables de impartir La hora del cuento parece que tienen una idea favorable en torno a la lectura:

B. La lectura es muy importante y más cuando estás en la escuela, aprendes y puedes tener mucha información, por eso aquí en la biblioteca les decimos a los niños que es muy importante leer y por eso los acercamos a los libros que tenemos y también les decimos que saquen su tarjeta de préstamo para que se lo lleven a su casa.

E. ¿Y tú lees?

B. Leo cuando tengo tiempo, aquí en la biblioteca hay muchas cosas que hacer, por ejemplo también yo soy la encargada del proceso de los libros (clasificarlos, etiquetarlos, darlos de alta en la base de datos y llevarlos a estantería) y a veces hojeo los libros y a veces leo fragmentos de textos pues para saber de qué tratan y poder recomendar a los usuarios.

E. ¿Qué lees en la biblioteca?

B. Pues como te decía, los libros nuevos que llegan, a veces leo la contraportada o partes para saber de qué tratan y poder recomendar a los usuarios, algunos los he leído completos por ratos, y también leo cuando preparo alguna actividad de la hora del cuento por ejemplo, me gusta leer revistas hay algunas que me han servido para las tareas de mis hijos...

E. ¿Y fuera de la biblioteca lees, por ejemplo, en tu casa?

B. Cuando llega a la casa me absorben el quehacer, la comida, lavar la ropa, atender a mis hijos.

E. ¿Ayudas a tus hijos en las tareas?

B. Sí, las tareas de mis hijos las hacemos aquí en la biblioteca, ellos están chicos todavía, uno es de primaria y otro de secundaria, aquí me pongo con ellos, les reviso, usamos algunos libros de aquí y a veces les digo que llegaron libros nuevos y cuando acabamos la tarea a veces ellos eligen libros y los leen mientras llega mi hora de salir (entrevista bibliotecaria 1).

De igual forma, la otra bibliotecaria entrevistada manifestó que es importante la lectura para estudiar:

B. Leer es para estudiar, tienes que leer bien para aprender, leer bien es que entiendas todo lo que dicen los libros.

E. ¿Qué es lo que lees?

B. Bueno, cuando tengo tiempo leo las revistas que llegan, leo el periódico todos los días. 


\section{E. ¿Aquí en la biblioteca o en tu casa?}

B. Aquí en la biblioteca, en mi casa no tengo chance de leer, tengo que hacer quehacer de la casa y comida y hago lonche para mí y para mis hijas, vivo lejos de la biblioteca y tengo llevar a mis hijas a la escuela, están en el turno vespertino, las dejo y me vengo a la biblioteca y luego me dan permiso de recogerlas y regreso a seguir trabajando.

E. ¿Y para las actividades que haces en la biblioteca?

B. Me toca hacer de todo, cuando tengo que preparar alguna actividad trato de leer el cuento antes de que lleguen los niños y ya luego los pongo a que dibujen algo (entrevista bibliotecaria 2).

Como observamos, la lectura es un medio de adquisición de información para ocupaciones escolares y como parte de la faena laboral de bibliotecaria, pero no existe la idea de una lectura propia más allá de la obligación o la tarea de un estudiante. La lectura se vuelve un medio para la adquisición de aprendizaje dirigido por los instructores escolares.

Una de las usuarias-lectoras de La hora del cuento manifiesta que existe diferencia entre lo que se refiere a la lectura en la escuela y en la biblioteca:

UL. La lectura es para estudiar para aprender, yo cuando leo y no entiendo, vuelvo a leer y leo página por página para poder responder las preguntas que me hacen en la escuela y hacer las tareas [...], el buen lector es el que lee bien y entiende todo, por eso hay que leer y leer hasta entender [...] a mí me gusta leer, en mi casa tengo muchos libros, mis papás y mis tíos me compran, me gusta estudiar [...] creo que soy buena lectora.

E. ¿Y aquí en la biblioteca?

UL. Aquí en la biblioteca me gusta venir a leer, vienen mis amigas, yo le pido a mi mamá que me traiga, platicamos y leemos, vemos cuentos [...] he llevado libros a mi casa de los que prestan, pero creo que yo tengo mejores libros que los que tienen aquí, me han gustado más, algunos de los [libros] que tienen aquí yo ya los había leído en mi casa desde antes.

E. ¿Es lo mismo leer para la escuela que en la biblioteca?

UL. Aquí lees cuentos, los cuentos son más fáciles, es como leer la realidad [...], y me gusta platicar con mis amigas y hacemos dibujos y platicamos de lo que hacemos.

E. ¿Y en tu casa?

UL. En mi casa leo cuentos y es más cómodo porque me puedo acostar (entrevista usuario-lector, diez años).

Lo que este fragmento nos muestra son nociones de la entrevistada sobre características del buen lector, y hace hincapié en la necesidad de comprender lo que se lee, además de reconocer que en el espacio bibliotecario tiene la oportunidad de socialización. Esas nociones son compartidas por otra de las usuarias-lectoras:

UL. Leer es para saber, para hacer la tarea de la escuela y aprender.

E. ¿Te consideras buena lectora? 
UL. Creo que no, es que le digo me cuesta trabajo aprender algunas cosas de la escuela y la tarea.

E. ¿Y leer en la biblioteca?

UL. Aquí sí me gusta, me gustan los cuentos, los personajes, cuando hacemos obras de teatro y venir a los talleres, hacemos manualidades, me gusta y platico con mis amigas...

E. ¿En tu casa tienes libros y cuentos?

UL. Libros de la escuela sí, cuentos no, por eso vengo; un día vine a hacer una tarea y me dijeron de que cuentan cuentos, me quedé y me gustó y, además, ahora tengo amigas con las que leemos, por eso vengo (entrevista a participante 2, once años).

Como observamos, los participantes que interactúan en este escenario de lectura coinciden en la idea de lectura asociada al desempeño escolar; mientras, la lectura en la biblioteca admite un carácter lúdico y de convivencia con otras personas, mediante textos y actividades diferentes a los empleados en la escuela. De esta forma, la lectura compartida de cuentos cumple con la función de la biblioteca de promover la lectura y difundir las colecciones presentes en ese espacio (Bolaños, 2015).

\section{Materiales, actividades y fines de lectura en la biblioteca}

En esta biblioteca se difunden actividades de fomento de la lectura en varios carteles que se ubican en la entrada y pasillos: La hora del cuento, el Círculo de lectura, las Tertulias y las Visitas guiadas. Sin embargo, durante el periodo de observación solo hubo participantes para la primera, por lo que elegimos esta para focalizar las observaciones sobre prácticas de fomento de la lectura y formación de lectores; llevamos a cabo seis registros de un grupo de cinco niñas con una edad entre los nueve y once años que asistieron de manera regular a esta actividad los jueves a las cinco de la tarde.

De acuerdo con lo visto, el espacio donde se lleva a cabo La hora del cuento es la sala infantil, con mobiliario en mal estado y sin una ambientación alusiva a la lectura ni a los niños, como debería ser si seguimos lo establecido en el manual que a cada biblioteca le proporciona la DGB. Alrededor se encuentran estantes con libros de todas las áreas acomodados conforme al Sistema de Clasificación Decimal Dewey.

En lo referente al foco principal de observación, La hora del cuento, una de las primeras cuestiones tiene que ver con el material que se utiliza. Los textos elegidos son cuentos para niños y niñas que, según los encargados, son comprensibles, con letras grandes y dibujos:

... por lo general si son niños chiquitos me fijo en que el texto tenga muchas imágenes y poco texto, también a veces me fijo en la parte de atrás del libro y ahí dice para qué edad se recomienda, si son niños más grandes, pues veo de lo nuevo que llegó a la biblioteca algo así que les llame la atención, así como de moda (entrevista bibliotecaria 1).

... yo elijo libros así con muchas imágenes y colores y letras grandes, casi siempre me tocan los niños chiquitos, son niños chiquitos que ya saben leer, cuando son más grandes, digamos de cuarto, quinto o sexto pues ya otros libros así con más letras que dibujos (entrevista bibliotecaria 2). 
Llama la atención que, aun cuando ninguno de los dos bibliotecarios entrevistados hace referencia al manual de capacitación de fomento de la lectura, ofrecen a los niños materiales adecuados para leer, en parte, porque los han revisado previamente (parte de la colección del área infantil en la contraportada indica la edad de los niños a los cuales se dirigen los textos). En el caso de la biblioteca observada, el personal que se hace cargo de las actividades de fomento tiene entre quince y veinte años de antigüedad en su trabajo; su formación la adquirieron en los cursos que la coordinación estatal y nacional de bibliotecas les ha proporcionado.

En cuanto a la disponibilidad, los usuarios-lectores que participan en La hora del cuento no tienen acceso libre a los textos, porque en la biblioteca no se dispone de un número suficiente de libros para que cada uno de los participantes tenga un ejemplar; por ello, los bibliotecarios acuden al fotocopiado del texto; incluso, en ocasiones, no se le proporciona a cada niño o niña un juego completo de copias del cuento; hacen una copia y la reparten entre los participantes para que puedan compartir la lectura colectiva. Este uso de las fotocopias permite, en parte, apreciar lo señalado en otros contextos de lectura en los que se cuestiona si se provoca una lectura fragmentada, poco reflexiva y descontextualizada (Henao y Castañeda, 2000; Carlino, 2001; Calderón-Ibáñez y Quijano-Peñuela, 2010). Otra de las opciones que utilizan los bibliotecarios para que los asistentes participen en la lectura es que el texto original lo circulan entre los participantes o también el bibliotecario lee en voz alta y muestra a los niños imágenes del cuento.

Los niños usuarios-lectores, por su parte, pareciera que consideran el material fotocopiado como un medio para participar en la dinámica de lectura establecida, pero no como un objeto con valor para que otros también lean, porque, cuando terminan la lectura, desechan el material.

Además de los cuentos o los libros usados por los bibliotecarios para promover la lectura, en una de las salas se montó la exposición "El universo en la punta del lápiz", que consistía en doce cuadros de ilustraciones de autores nacionales e internacionales. La bibliotecaria, en una de las sesiones de La hora del cuento, antes de llevar a los usuarios-lectores participantes de la actividad, los dirigió hacia la exposición para que observaran los cuadros; pidió comentarios a los niños de cada una de las imágenes y que leyeran en voz alta la ficha técnica de cada cuadro. Mediante esa parte de la actividad, es posible promover el acercamiento a la lectura en los términos que proponen Álvarez y Naranjo (2003), dado que no se centra solo en los libros, sino que abarca otras experiencias de ámbitos sociales y culturales que permiten apreciar la lectura como parte de la vida cotidiana.

Como ya mencionamos, los textos que se utilizan por lo regular son cuentos cortos y la lectura grupal e individual en voz alta se realiza casi siempre de la misma manera. Esos textos son elegidos todas las veces por el responsable de llevar a cabo la actividad, con base en criterios adquiridos en los talleres de capacitación de fomento a la lectura y las indicaciones del manual que en cada biblioteca se encuentra.

La dinámica consta de la lectura en voz alta de un cuento por lo general corto, entre seis y diez páginas, con letra grande y dibujos, unas seis o siete líneas de lectura por página. La lectura la hace el bibliotecario con la participación voluntaria de los 
usuarios-lectores; en ocasiones, el bibliotecario asigna turnos y partes de la lectura. Es importante señalar cómo las actividades de lectura se ligan con algo más, por ejemplo, con un dibujo o con alguna manualidad; para el personal entrevistado, lo anterior es importante como evidencia de trabajo:

B. Después de terminar con el cuento, se les da una hoja y colores para que hagan un dibujo, puede ser de una escena del cuento o de uno de los personajes...

E. ¿En todas las ocasiones en que llevan a cabo la hora del cuento o una actividad de lectura con los usuarios realizan algo después de la lectura?

B. Sí, casi siempre a los niños les gusta, se lo llevan a su casa y les dicen a sus papás lo que hicieron en la biblioteca, a veces nos quedamos con algunos para cuando entregamos informes de los asistentes a la biblioteca y de las actividades que realizamos. Se hace un registro de usuarios que asisten a consultar libros y cuando hacemos talleres como manualidades, por ejemplo, un marco de palitos y le pegamos una foto o un dibujo que el niño y a veces nos los dejan, eso lo mandamos en el informe.

Otras actividades derivadas de la lectura con base en el cuento implican ejercicios de escritura, en este caso, escribir una carta; aunque en un principio se negaron los usuarios-lectores, la bibliotecaria que desarrolla la actividad logró convencerlos y les ayudó con algunas partes que integran este tipo de documento. Con ello se consigue, en cierto modo, lo señalado por Ferreiro (2008) y Pellicer (2009), quienes afirman que la lectura y la escritura, al darse en conjunto, favorecen una revaloración de lo leído.

Sin embargo, este tipo de actividades necesitan más tiempo que la lectura de textos y la construcción de significado sobre lo leído, como señala Duarte (2005); esto se corrobora en el hecho de que se invirtieron ocho minutos en leer el texto y en escribir la carta se contabilizó, desde la instrucción hasta que terminó el primer participante, cuarenta minutos. Algunas fueron leídas de manera voluntaria, pero no se revisaron ni hubo retroalimentación de la persona a cargo de aspectos como la ortografía o la sintaxis. En otra ocasión, los usuarios-lectores que participaron en La hora del cuento ensayaron una obra de teatro, la cual pretendían presentar el Día de las Madres. En este ensayo cada una de los participantes hacía las voces del personaje que le tocó; para leer, tenían en sus manos en fotocopia la parte del diálogo del personaje que representarían.

En cuanto a los fines de la lectura, podemos afirmar que en esta biblioteca predomina, por una parte, la difusión del acervo y, por otra, el fomento del interés de los usuarios por acercarse a libros diferentes a los textos escolares, como, por ejemplo, textos narrativos de moda; esto se refleja en lo que dicen, respectivamente, los bibliotecarios:

E. ¿Cuáles son los objetivos de las actividades de la biblioteca?

B. La función principal es atender a los usuarios, la otra es dar a conocer los libros que hay y que llegan, por ejemplo, en ocasiones, cuando haces alguna actividad con los niños el cuento lo dejas sin terminar o medio les cuento el final para que ellos vengan, y luego me preguntan ¿tiene el libro en la biblioteca?, ¿sí lo presta? Y le contestamos: “Sí, ve y haz tu trámite de la credencial, te lo prestamos por ocho días y te lo llevas a tu casa".

E. ¿Y han venido a buscar el libro esos niños que se quedan con la duda? 
B. Sí, si han venido a buscar, tramitan su credencial y ya se llevan el libro, ya luego vienen con mi compañero o conmigo y nos dicen: "Aquí está el libro, sí me gustó" y entonces les decimos: "Mira tenemos más, están tales títulos[...] hay muchos libros donde puedes sacar información".

E. ¿Cuáles son los objetivos de las actividades de la biblioteca?

B. Pues [...] yo creo que lo importante es que la gente venga y lea o se lleve los libros a su casa, que se usen los libros.

Con relación a los recursos digitales, hay algunas obras clásicas y otros materiales audiovisuales, aunque estos últimos no fueron utilizados durante las sesiones de observación. En lo concerniente a la organización, disponen del catálogo digitalizado y se conserva el tradicional (urnas de metal con tarjetas) "por si acaso falla el que se revisa en la compu" (menciona una de las bibliotecarias entrevistadas). A pesar de que hay un letrero en el que se anuncia el servicio del uso de las computadoras e internet gratuito, los días que realizamos las observaciones y entrevistas no se registró el uso de ese servicio, pues no estaba habilitado.

Los bibliotecarios recurren a los equipos de cómputo y a internet -cuando lo tienen- para encontrar material que les ayude a complementar las actividades de fomento a la lectura, por ejemplo, buscan dibujos alusivos al tema del cuento que utilizarán, lo imprimen, fotocopian y reparten entre los asistentes para que luego ellos los coloreen.

Lo anterior nos muestra cómo, en un espacio institucional no escolar como el de la biblioteca pública, las prácticas de lectura se desarrollan y configuran a partir del texto; los fines para los cuales se realizan tienen como centro el uso y la consulta de los libros, a diferencia de lo reportado en otros escenarios de lectura, como el laboral y el escolar universitario (González, 2013). La tarea central de quienes trabajan en la biblioteca es "cuidar" el comportamiento de los usuarios que asisten para que consulten los libros y participen en las actividades de lectura de acuerdo con lo establecido; por ello, se dan a conocer en este contexto rutinas de acceso y participación de la lectura (Hamilton, 2000; Caro, 2013).

\section{Hallazgos}

En este trabajo hemos dado cuenta de prácticas de lectura que se promueven en la biblioteca pública con las que, en principio, se pretende favorecer en los usuarios un interés por la lectura. Los datos recabados nos permitieron identificar la existencia de "protocolos de lectura" (Chartier, 2002) asociados a las características del material y a su estructura, en este caso del cuento. Estos protocolos son establecidos por quienes validan la interpretación de los textos, y dan lugar a ciertas maneras de leer según los textos en conjunción con los contextos (Barton \& Hamilton, 1998, 2000; Rockwell, 2001).

Como quedó registrado, el acceso a los textos está determinado por el bibliotecario al igual que las formas y los tiempos de participación en las acciones de lectura. Se privilegia la lectura en voz alta en grupo sobre la lectura en silencio e individual; después de la lectura se desarrolla una actividad asociada a la lectura, como una 
tarea con la que se pueda dar cuenta de lo leído. Durante la lectura en voz alta se corrige a quienes pronuncian mal una palabra o se equivocan en lo leído; algo que no sucede, no de manera expresa, es la evaluación de la actividad.

Respecto a las niñas que fueron observadas, apreciamos motivación hacia los textos que formaron parte de La hora del cuento, posiblemente por tratarse de contenido de carácter narrativo. No obstante, podría esperarse que también se aprovechara esta actividad para incidir en la mejora de algunos aspectos de su práctica lectora incipiente, aunque eso no ocurrió; por ejemplo, casi no encontramos evidencia de que se aprovecharan los fragmentos en los que una niña leía en voz alta para verificar que tuviera una correcta entonación del texto, o bien, instruirlo para generar inferencias de significados sencillos o corregir errores puntuales de lectura, como añadir palabras que no están en el texto (autocompletarse) u omitir palabras que sí están, cambiar palabras (decir una cosa por otra).

Analizar las prácticas de lectura que se llevan a cabo en algún espacio en particular, sin duda, ofrece elementos para dilucidar lo complejo que es el fenómeno lector. Las maneras en las cuales se valora la lectura y los textos en un contexto determinado influyen en las formas de leer que se dan y van delineando creencias y consideraciones acerca de la lectura. Una característica del espacio al que accedimos en este sentido es la escasez de usuarios en general en la biblioteca, principalmente de usuarios adultos. El registro de personas que asisten adquiere más importancia por ese motivo que la formación de lectores. Las prácticas lectoras en la biblioteca pública están centradas en el libro y su difusión, y en poner a disposición de todo el público la variedad de materiales de lectura con los que cuenta. No obstante, aunque pocos, también encontramos elementos para apreciar el fomento de la lectura en términos de la promoción del uso eficaz de textos para satisfacer inquietudes recreativas.

\section{CONCLUSIONES}

La biblioteca pública, de acuerdo con los antecedentes presentados, tendría que cumplir una función de lugar de acceso a información y difusión de cultura y conocimiento. Sin embargo, el hecho de que durante el periodo en el que se realizaron las observaciones prácticamente no hubo asistencia de usuarios adultos llama a la reflexión acerca de dos cuestiones:

-Que entre los potenciales usuarios se cuente con el mismo significado del espacio representado por la biblioteca pública.

-Que existan circunstancias concretas por las cuales no la visitan, como podría ser el desplazamiento de la biblioteca pública ante la emergencia de las fuentes electrónicas de información accesibles desde dispositivos móviles.

La biblioteca, por una parte, es el lugar donde "la lectura es escasa", el libro es el objeto de las actividades laborales de los bibliotecarios, se promueven y desarrollan actividades que motiven a la lectura y, por otra, los libros de la biblioteca y su lectura en ese espacio provocan que un grupo de niñas y niños se reúnan, compartan la lectura y convivan con sus amigas y amigos; desde esta perspectiva, la biblioteca pública cumple su función, aunque de manera austera, al promocionar los libros y alcanzar a la comunidad. 


\section{REFERENCIAS BIBLIOGRÁFICAS}

Agustín, M. y Morera, E. (2016). Los clubes de lectura en Aragón: análisis descriptivo de una práctica socio-cultural de animación y promoción lectora. Revista General de Información y Documentación, vol. 2, núm. 26, pp. 583-603. Recuperado de https://revistas.ucm.es/index.php/RGID/article/ view/54716/49919

Almada, M., Duarte, M., Etchemaite, F. y Seppia, O. (2001). Entre libros y lectores II. Promoción de la lectura y revistas. Buenos Aires: Lugar Editorial.

Álvarez, C. (2016). Clubs de lectura. ¿Una práctica relevante hoy? Información, Cultura y Sociedad, núm. 35, diciembre, pp. 91-106. Recuperado de http:// revistascientificas.filo.uba.ar/index.php/ICS/article/view/2512/2664

Álvarez, D., Giraldo, Y., Rodríguez, G. y Gómez, M. (2008). Acercamiento al estado actual de la promoción de la lectura en la Biblioteca Pública en Colombia. Revista Interamericana de Bibliotecología, vol. 2, núm. 3, pp.13-43. Recuperado de https://revistas.udea.edu.co/index.php/RIB/article/view/1883/1555

Álvarez, D. y Naranjo, E. (2003). La animación a la lectura: manual de acción y reflexión. Medellín: Edilma. Universidad de Antioquia, Escuela Interamericana de Bibliotecología.

Argüelles, J. (2002). Los usos de la lectura en México. La Colmena: Revista de la Universidad Autónoma del Estado de México, núm. 35-36, pp. 55-64. Recuperado de https://lacolmena.uaemex.mx/article/view/6438/5041

Arnal, J., Del Rincón, D. y Latorre, A. (1992). Investigación educativa. Fundamentos y metodología. España: Labor.

Barton, D. \& Hamilton, M. (2000). Literacy practices. En Barton, Hamilton e Ivaníc. Situated literacies, reading and writing in context (pp. 7-15). Routledge: Nueva York.

Barton, D. \& Hamilton, M. (1998). Local literacies. Reading and writing in one community. Londres: Routledge.

Bermúdez, D. (2012). El lector legitimado: dime qué lees y veré si te saludo. Recuperado de http://totocologo.blogspot.mx/2012/04/el-lector-legitimadodime-que-lees-y.html

Bolaños, M. (2015). El papel de la biblioteca pública en la formación de lectores. En S. Sánchez-García y S. Yubero (coords.). Las bibliotecas en la formación del hábito lector (pp. 91-126). España: Ediciones de la Universidad de Castilla-La Mancha.

Calderón-Ibáñez, A. y Quijano-Peñuela, J. (2010). Características de comprensión lectora en estudiantes universitarios. Revista Estudios Socio-jurídicos, vol. 1, núm. 12, pp. 337-364. Recuperado de https://revistas.urosario.edu.co/index.php/sociojuridicos/article/view/1195/1131

Carlino, P. (2005). Escribir, leer y aprender en la universidad. Buenos Aires: Fondo de Cultura Económica.

Carlino, P. (2001). Hacerse cargo de la lectura y la escritura en la enseñanza universitaria de las ciencias sociales y humanas. I Jornadas sobre la lectura y la escritura como prácticas académicas universitarias. Departamento de Educación, Universidad Nacional de Luján, Luján, Provincia de Buenos Aires, diciembre. Recuperado de https://www.aacademica.org/giceolem/box/paula. carlino/178.pdf 
Caro, J. (2013). Algunas aproximaciones a las prácticas de lectura y escritura en la biblioteca pública. Códices, vol. 2, núm. 9, julio-diciembre, pp. 11-25. Recuperado de https://cnb.gov.co/codices/online/Vol9-2013II.pdf

Centro Regional para el Fomento del Libro en América Latina y el Caribe (CERLALC) (2012). Programa Iberoamericano de Bibliotecas Públicas. Recuperado de http://www.cerlalc.org/redplanes

CERLALC (2007). Plan Iberoamericano de Lectura ILIMITA. Colombia.

CERLALC (2004). Agenda de políticas públicas de lectura. Colombia: CERLALCILIMITA. Recuperado de http://cerlalc.org

Consejo Nacional de Población (Conapo) (2012). Índice de Marginación Urbana 2010. México. Recuperado de http://www.conapo.gob.mx/es/CONAPO/ Indice_de_marginacion_urbana_2010

Consejo Nacional para la Cultura y las Artes (Conaculta) (2003). Hacia la formación de lectores en la biblioteca pública. Ideas y estrategias para el bibliotecario. México.

Chartier, R. (2002). Del libro a leer. En R. Chartier. Prácticas de la lectura (pp. 61-86). La Paz: Plural.

Dirección General de Bibliotecas (DGB) (2013). Red Nacional de Bibliotecas Públicas. Antecedentes. Recuperado de http://dgb.conaculta.gob.mx/info_detalle.php?id=7

DGB (2002). Fichero de actividades de fomento a la lectura en las bibliotecas públicas. México: Conaculta.

Duarte, M. (2005). Promoción de la lectura o formación de lectores. Diálogos Pedagógicos, vol. 5, núm. 3, abril, pp. 42-55. Recuperado de http://revistas. bibdigital.ucc.edu.ar/index.php/prueba/article/view/387/pdf

Ferreiro, E. (2008). Acerca de las rupturas o continuidades en la lectura. En M. Borrero (comp.). Lecturas complementarias para maestros. Leer y escribir con niños y niñas (pp. 79-92). Bogotá: Fundalectura y Funda Corona.

García-Gómez, F. y Díaz-Grau, A. (2007). Formación de usuarios y alfabetización informacional: dinámicas de trabajo en bibliotecas públicas. En R. Gómez (ed.). Acción pedagógica en instituciones artísticas y culturales (pp. 215-247). Vitoria-Gateiz: Grupo Xabide. Recuperado de http://eprints.rclis. org/10694/1/FU_ALFIN_BPxabide.pdf

González, Y. (2013). La lectura en contextos laborales y escolares. Guadalajara: Universidad de Guadalajara.

Hamilton, M. (2000). Expanding the new literacy studies: Using photographs to explore literacy as social practice. En D. Barton, M. Hamilton \& R. Ivanič (eds.). Situated literacies: Reading and writing in context (pp. 16-34). Londres: Routledge.

Henao, J. y Castañeda, L. (2000). Consideraciones sobre la lectura en el medio universitario. Ikala, Revista de Lenguaje y Cultura, vol. 1, núm. 5, pp. 7-24. Recuperado de https://revistas.udea.edu.co/index.php/ikala/article/ view/8543/7884

Hernández, H. (2001). Diez reflexiones en torno a la biblioteca y a la información en las bibliotecas públicas. Revista Interamericana de Bibliotecología, vol. 2, núm. 24, julio-diciembre, pp. 113-122. Recuperado de https://revistas. udea.edu.co/index.php/RIB/article/view/3204/2968 
IFLA/Unesco (2010). Manifesto for Digital Libraries. Recuperado de http:// www.ifla.org/node/2340

IFLA/Unesco (1999). School Library Manifesto 1999. Recuperado de http:// www.ifla.org/ES/node/7273

IFLA/Unesco (1994). Public Library Manifesto 1994. Recuperado de http://archive.ifla.org/VII/s8/unesco/span.htm

Kalman, J. (2002). La importancia del contexto en la alfabetización. Revista Interamericana de Educación de Adultos, vol. 3, pp. 11-28. Recuperado de http:// files.eric.ed.gov/fulltext/ED482882.pdf\#page $=11$

Labra, J. P. (2005). Animación a la lectura y TIC: creando situaciones y espacios. Revista de Educación, número especial, pp. 255-279. Recuperado de http://www.revistaeducacion.mepsyd.es/re2005/re2005_19.pdf

Larrosa, J. (2003). La experiencia de la lectura. Estudios sobre literatura y formación. México: FCE.

Margaix-Arnal, D. (2008). Informe APEI sobre web social. Gijón: Asociación Profesional de Especialistas en Información. Recuperado de https://dspace-libros.metabiblioteca.com.co/bitstre am/001/187/4/978-84-691-7726-6.pdf

Martos, E. y Guerrero, M. (2011). Educación emprendedora y lectura. Puertas a la Lectura, núm. 23, diciembre, pp. 4-28. Recuperado de dialnet.unirioja.es/ descarga/articulo/4027954.pdf

Moreno, M. (2005). Potenciar la educación. Un currículum transversal de formación para la investigación. Revista Electrónica Iberoamericana sobre Calidad, Eficacia y Cambio en Educación, vol. 1, núm. 3, pp. 520-540. Recuperado de http://www.ice.deusto.es/rinace/reice/vol3n1_e/Moreno.pdf

Niegaard, H. (1994). Unesco's 1994 Public library manifesto. Presentado en Proceedings of the 60th IFLA Council and General Conference, München, Saur. Recuperado de http://www.ifla.org

Pautas Pulman (2002). Public Libraries Mobilising Advanced Networks. Recuperado de http://www.pulmanweb.org/DGMs/DGMs.htm

Pellicer, A. (2009) Promoción de la lectura. El contexto educativo para la formación de lectores. En A. de Alba y R. Glazman (coords.). ¿Qué dice la investigación educativa? (pp. 83-112). México: COMIE.

Pérez, A, y Gómez, M. (2010). La biblioteca escolar: lectura, TICs y familia. En J. Calixto. Bibliotecas para a vida II -biblioteca e leitura, del 18 al 21 noviembre 2009 (pp. 265-280). Lisboa: Colibrí CIDEHUS/EU -Centro Interdisciplinar de História, Culturas e Sociedades da Universidade de Évora. Recuperado de http://eprints.rclis.org/17544/1/EvoraFinal.pdf

Ortega, F. (2006). Trayectorias y prácticas de lectura en la biblioteca pública: un estudio etnográfico en el municipio de Chalco, Estado de México. Lectura y Vida: Revista Latinoamericana de Lectura, vol. 1, núm. 27, pp. 3041. Recuperado de http://www.lecturayvida.fahce.unlp.edu.ar/numeros/ a27n1/27_01_0rtega.pdf

PISA/OCDE (2000, 2003, 2006, 2009, 2012, 2015). Informes. Recuperado de www.oecd.org/centrodemexico/laocde

Rockwell, E. (2001). La lectura como práctica cultural: conceptos para el estudio de los libros escolares. Educação e Pesquisa, vol. 1, núm. 27, pp. 11-26. Recuperado de https://www.scielo.br/pdf/ep/v27n1/a02v27n1.pdf 
Sevilla, M. (2007). Dentro de la Biblioteca Glo-cal: ¿usuarios, clientes o simplemente público? Revista General de Información y Documentación, vol. 2, núm. 17, pp. 95-102. Recuperado de https://revistas.ucm.es/index.php/RGID/article/view/RGID0707220095A/9399

Stake, R. (2000). Case studies. En N. K. Denzin \& Y. S. Lincoln (eds.). Handbook of Qualitative Research (pp. 435-454). Thousand Oaks, CA: Sage.

Stake, R. (1978). The case study method in social inquiry. Educational Researcher, vol. 2, núm. 7, pp. 5-8.

Yépez, L., Ceretta, M. y Díez, C. (2013). Jóvenes lectores. Caminos de formación. Uruguay: Ministerio de Educación y Cultura. Recuperado de http://cerlalc. org/wp-content/uploads/2013/10/JovenesLectores2013-.pdf

Yin, R. (1984). Case study research: design and methods. Londres: Sage.

Zavala, V. (2011). La escritura académica y la agencia de los sujetos. Cuadernos Comillas, núm. 1, pp. 52- 66. Recuperado de http://s3.amazonaws.com/ academia.edu.documents/32528247/5_zavala.pdf?AWSAccessKeyId=AKI AJ56TQJRTWSMTNPEA\&Expires $=1471737349 \&$ Signature $=V J 5 D$ fieb15Hih S5X94Eo4pNV1Zw\%3D\&response-content-disposition=inline $\% 3 \mathrm{~B} \% 20$ filename\%3DVirginia_Zavala_La_escritura_academica_y.pdf 